\title{
Effects of Eugenol on Memory Performance, Neurogenesis, and Dendritic Complexity of Neurons in Mice Analyzed by Behavioral Tests and Golgi Staining of Brain Tissue
}

\author{
Akbar L', Juliandi B², Boediono A³, Batubara I,5, Subangkit $\mathrm{M}^{6}$
}

\begin{abstract}
Eugenol, as the main component in clove, has neuroprotective abilities, including its effect to learning memory of mice. However, there is no evidence showing whether eugenol can expand the growth of dendrites in the brain. The objective of this research was to examine the effects of eugenol towards dendritic complexity of neurons, neurogenesis, and memory performance in hippocampus. A total of 21 mice were divided into three groups; (i) mice were administered $30 \mathrm{mg} / \mathrm{kg}$ bw eugenol orally, (ii) mice were administered $100 \mathrm{mg} / \mathrm{kg} \mathrm{bw}$ eugenol orally, and (iii) mice were administered distilled water as control. Mice were kept for 30 consecutive days following the standard animal housing. The memory performance was observed through the Y-arm maze alternation, Novel Object Recognition (NOR), and Morris Water Maze (MWM) test. The brain was dissected and stained with FD Rapid Golgi Staining ${ }^{T M}$ kit to observe dendrites in the dentate gyrus (DG) and cornu ammonis 1 (CA1) region; and Haematoxylin-Eosin (HE) staining to assess neurogenesis in the DG. Our results showed that eugenol enhanced putative neural stem cells (NPCs) and granular cells (GC) number, and also decrease neuronal cell death in DG $(\mathrm{p}<0.0001)$. Eugenol also increased dendritic complexity of neurons in DG region; while in CA1, eugenol has given a positive effect only on the basal area. Eugenol increased spatial and recognition memory in mice, indicated by a higher number of correct alternations and discrimination ratio compared to the control group $(\mathrm{p}<0.05)$, although escape latency in MWM did not show significant effect $(\mathrm{p}>0.05)$. As analyzed by behavioral tests and Golgi staining of brain tissue, eugenol can increase memory performance, neurogenesis, and dendritic complexity of neurons in the DG and CA1 basal region of brain in mice.
\end{abstract}

Key Words: Dendrites; Eugenol; Hippocampus; Neurogenesis; Memory

\section{Introduction}

Bioprospecting of biologically active compounds from plants has emerged in recent centuries for developing a natural medicine. Numerous medicinal plants have been screened both in vitro and in vivo for investigating new potential drugs ${ }^{[1]}$. Studies have suggested that traditional herbs are able to prevent or treat health problems $^{[2]}$. One of the plants that possess many pharmacological properties is clove (Syzygium aromaticum L.). Clove is a member of Myrtaceae family, which originates from the Maluku islands, Indonesia. Cloves oils are mainly composed of eugenol (4-allyl2-methoxyphenol; 72-90\%), which is an active compound that responsible for the clove's aroma ${ }^{[3]}$.

Eugenol has been shown to have several advantages such as an anticonvulsant activity ${ }^{[4]}$ anesthetic, antirepellent ${ }^{[5]}$, anticarcinogenic $^{[6]}$, slimming aromatherapy ${ }^{[7]}$ and amelioration of chronic inflammation ${ }^{[8]}$. It also have been shown to posses the ability as an antidepressant $\mathrm{t}^{[9]}$, antioxidant ${ }^{[10]}$, and neuroprotective ${ }^{[11]}$ which offers many benefits for an alternative therapeutic in neurodegenerative disorder, particularly for Alzheimer's disease ${ }^{[12,13]}$. This potency might be correlated with its ability to preserve memory in the brain. A previous report revealed that combining eugenol with acupuncture can boost the learning-memory ability through olfactory pathway ${ }^{[14]}$. This research is parallel to another study which has shown that eugenol can manage to decrease spatial memory loss in mice that induced by scopolamine ${ }^{[15]}$. This process of learning and storing memory is highly related to hippocampus in the brain ${ }^{[16]}$.

Hippocampus is a brain area known to be responsible for memory processing and neurogenesis, a process when the brain generates new neurons throughout life. In hippocampus, memory drives through the entorhinal cortex (EC), then transmitted from the dentate gyrus (DG) to the hippocampus proper (CA1, CA3), and finally transferred to many areas in the brain. This structure indeed is a pivotal part of the brain, thus any damages in this region will lead to cognitive dysfunction ${ }^{[17]}$. DG has been widely recognized for adult neurogenesis ${ }^{[18]}$, in which the neural progenitor cells (NPCs) will develop to be mature cells in the following process, such as proliferation, differentiation, and migration ${ }^{[19]}$. This hippocampal neurogenesis will give a good impact on cognitive performance by altering learning memory ability.

Eugenol is also reported to possess the ability in inducing brainderived neurotrophic factor (BDNF) in the hippocampus ${ }^{[20]}$. This protein has an ability to increase the number of dendritic pyramidal neurons and increase its dendritic growth and branches ${ }^{[21]}$. This 
condition will affect the increment of signal processing and functional network integrity, since dendrites are crucial in determining the signals received by a neuron ${ }^{[22]}$. They act as the key integrators of flux signal in synapses and also contribute to neuron plasticity ${ }^{[23]}$. However, the effect of eugenol administration towards neuronal dendrites of the brain have not yet been evaluated. Therefore, using behavioral and brain histological approaches, we examined the effects of eugenol on the hippocampal dendritic complexity of neurons and neurogenesis; and how it affects memory performance of the mice in this study.

\section{MATERIALS AND METHODS}

\section{Animal Treatment}

Twelve-week-olds male Deutchland Denken Yonken (DDY) mice (Mus musculus) weighing 20-25 grams were used in this study. Twenty one mice were divided into 3 groups each consisting 7 mice $(\mathrm{n}=7)$. Group I was administered with eugenol (TCI, Japan) $30 \mathrm{mg} / \mathrm{kg}$ $\mathrm{bw}^{[15,20]}$ (Eug30), group II was administered with eugenol $100 \mathrm{mg} / \mathrm{kg}$ $\mathrm{bw}^{[20]}$ (Eug100), and group III was administered by distilled water as control. Mice were acclimatized for 7 days before subjected to the treatment and mice were fed ad libitum and housed on a 12/12-h light cycle. All the dosages were given to mice pre-orally for 30 consecutive days. This experiment was approved by Animal Ethics Committee of IPB University (No. 73-2017.IPB). All efforts were made to minimize animal suffering in this research.

\section{Behavioral Test}

The behavioral tests to assess mice memory were conducted using $\mathrm{Y}$ maze alternation, Novel Object Recognition (NOR), and Morris Water Maze (MWM) tests. The Y maze and NOR tests was performed before and after treatments as described in the previous studies $^{[24,25]}$. The MWM test was performed based on previous study with some modifications ${ }^{[26]}$. The training phases were divided into visible platform trial (VPT) and hidden platform trial (HPT). The primary test consisted of short term memory (STM) and long term memory (LTM) test. There were 4 different start locations $(\mathrm{N}, \mathrm{S}, \mathrm{W}$, and $\mathrm{E})$. Mice were undergone training using distinct initial locations. VPT was conducted at day 7,8 and 9; HPT at day 10; STM at day 11; and LTM was conducted at day 33 .

\section{Analysis of Dendritic complexity of neurons and Cell Density}

Mice were anesthetized with ketamine $10 \mathrm{mg} / \mathrm{kg}$ bw and xylazine 1 $\mathrm{mg} / \mathrm{kg}$ bw. The brain was isolated from the skull and were processed into the FD Rapid Golgi Staining ${ }^{\mathrm{TM}}$ kit (FD NeuroTechnologies, Inc., USA) based on procedure from the manufacturer. The dendrites were analyzed using the Sholl Analysis. Dendritic tracing was performed on mature neurons. The parameters used in this research were dendritic length, intersection, and maximum dendritic span in the DG, CA1 apical, and CA1 basal. Another part of the brain was processed by routine embedding paraffin histology methods with Hematoxylin and Eosin (HE) staining for assessing neurogenesis by observing cells densities in $\mathrm{DG}^{[27]}$.

\section{Statistical Analysis}

Statistical analysis were performed with paired t-test, and One-way Analysis of Variance (ANOVA) followed by Tukey-HSD post hoc test for multiple group comparisons. Results were represented as means \pm SEM. This analysis was conducted using the $\mathrm{R}$ Software version 3.5.1 (www.r-project.org).

\section{RESULTS}

\section{Dendritic complexity of neurons in the DG and CA1}

Hippocampus is composed of different subregions that is highly interconnected, and its arrangement might suggest the computational functions to construct memory. The representative of hippocampus stained by Golgi staining is shown in Figure 1A, and the dendrites in DG and CA1 are shown in Figure 1B. In this region, dendrites develop and emerge as an important part to transmit the signals. Golgi staining was quantified to examine the characteristics of dendrites, namely dendritic length, intersections, and maximum dendritic span in the DG, and CA1 (apical and basal).

Administration of eugenol at dose of $100 \mathrm{mg} / \mathrm{kg}$ bw considerably increased dendritic length and number of intersections in DG area compared to control $(\mathrm{p}<0.001$; Tukey-HSD post hoc). This higher dosage was also different compared to $\operatorname{Eug} 30$ ( $<<0.01$; Tukey-HSD post hoc; Figure 1C). In apical part of CA1, no significant improvement has been detected ( $p>0.05$; ANOVA; Figure 1D). However, in basal part of CA1, both of dendritic length and intersections of Eug30 and Eug100 have increased and significantly different compared to control $(\mathrm{p}<0.0001$; Tukey-HSD post hoc; Figure 1E). We also found that the maximum dendritic span was not different among the groups in DG (Figure 1c) and apical part of CA1 ( $>0.05$; one way ANOVA; Figure 1d), although we have noticed a statistically different results in basal part of CA1 ( $<<0.05$; one-way ANOVA; Figure 1E). The number of intersection from soma also varied in each group (Figure $1 \mathrm{~F}-1 \mathrm{H}$ ).

\section{Neurogenesis in $D G$}

The neurogenesis in this research is represented by the three main indicators: the putative neural progenitor cells (NPCs), granular cells (GCs), and apoptotic cells density in DG of mice hippocampus. The representative of hippocampus with HE staining in each group is shown in Figure 2A. The number of putative NPCs density is increased in Eug100 ( $<<0.0001$; Tukey-HSD post hoc; Figure 2B), while the GCs density was also showed the similar trend, in which Eug30 achieved the highest density compared to other groups $(\mathrm{p}<0.0001$; Tukey-HSD post hoc; Figure 2C). The higher density of NPCs and GCs in treatment groups might have benefits for memory formation by providing new neurons, and also supports its dendrites development during the fate determination. In contrast, this research demonstrated that the apoptotic cells in both of eugenol treatments were massively decreased $(\mathrm{p}<0.0001$; Tukey-HSD post hoc; Figure 2D).

\section{The Effects of Eugenol on Memory Performance}

Y maze test was conducted based on the tendency of mice behavior to explore novel areas. In the normal stage before any treatments, all of the groups did not show any differences ( $p>0.05$; one-way ANOVA), the percentage of correct alternation was ranging at around $55-60 \%$, but after 30 days of eugenol treatment, we found that Eug30 ( $<<0.01$; paired t-test $)$ and Eug100 ( $<<0.001$; paired $\mathrm{t}$-test) have an increased and significantly different correct alteration percentage compared to control group ( $\mathrm{p}<0.05$; one way ANOVA). This study demonstrated that eugenol administration has a positive effect on the mice's spatial learning ability, and both dosages that given to mice were effective in improving spatial memory performance (Figure 2E).

In this research, we also counted the recognition memory by NOR test. This test has been widely used to evaluate the effect of a new drug on memory in animal model. By using this test, we exposed 
A

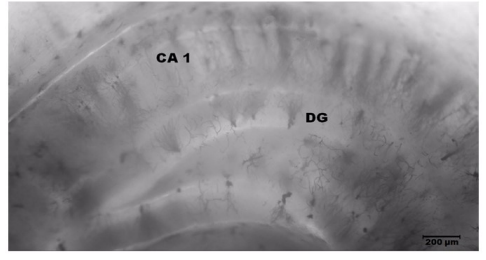

C

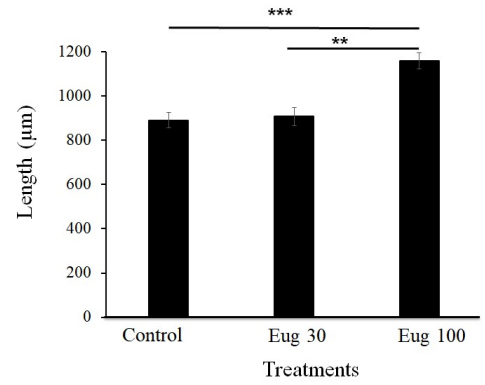

D

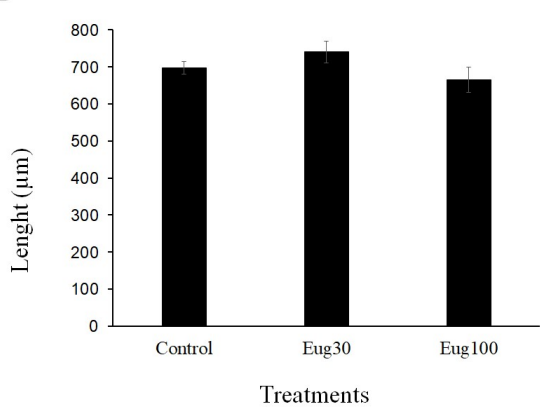

$\mathbf{E}$

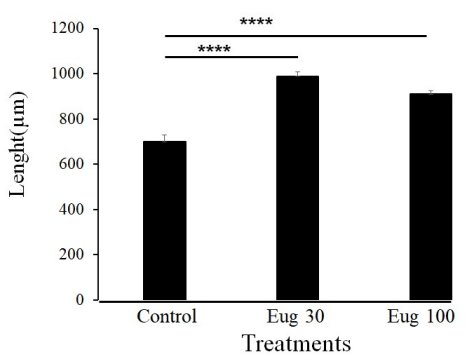

F

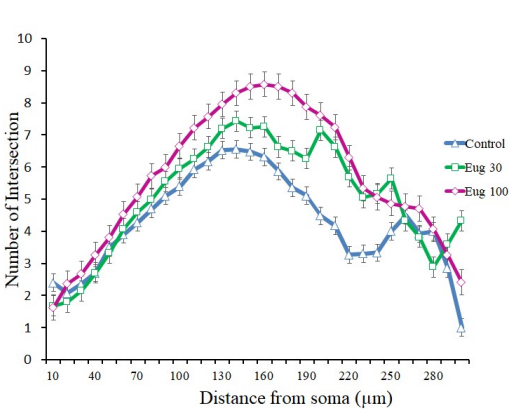

G
B

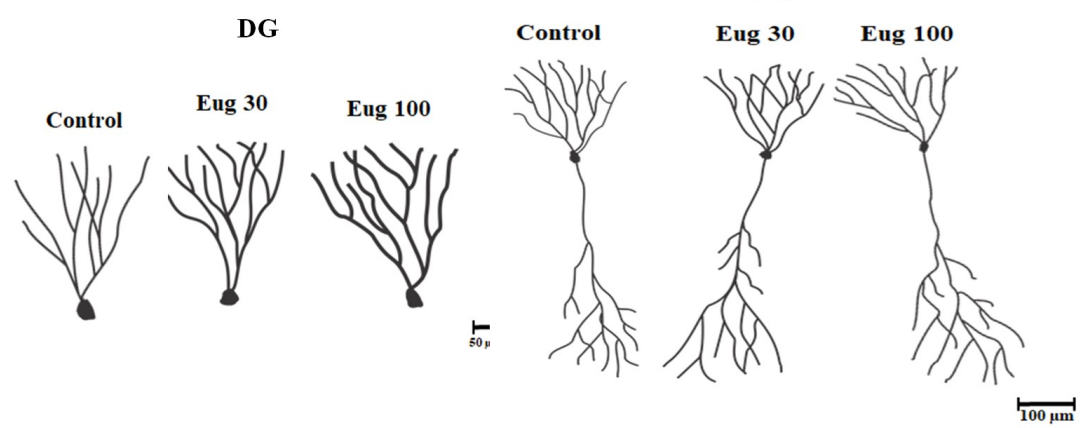

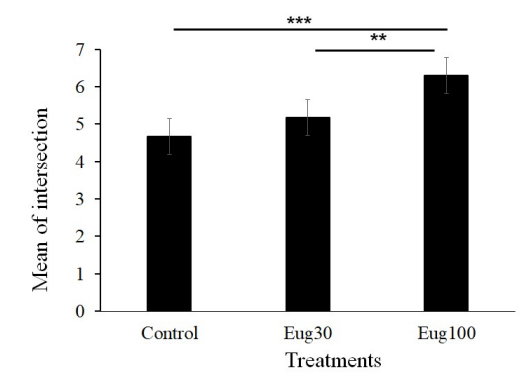
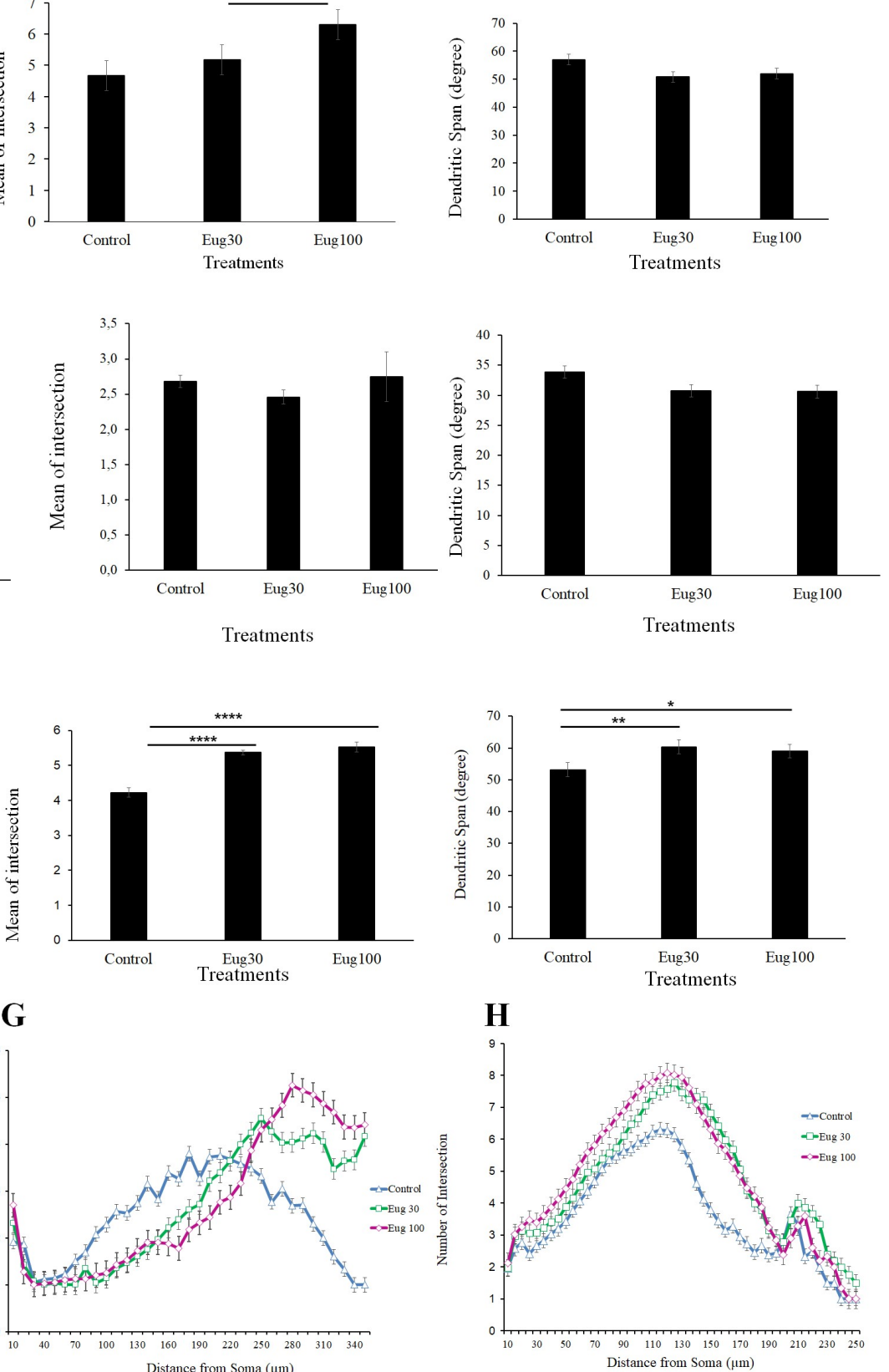

Figure 1: Dendritic complexity of neurons in hippocampus. (A) Representative of hippocampus using FD Rapid Golgi staining; (B) Representative of dendrites of control, Eug30, and Eug100 in DG and CA1; (C) Dendritic complexity of neurons in DG; (D) Dendritic complexity of neurons in apical part of CA1; (E) Dendritic complexity of neurons in basal part of CA1; (F) Number of intersection from soma in DG; (G) Number of intersection from soma in apical part of CA1; (H) Number of intersection from soma in basal part of CA1. * significantly different using one-way ANOVA followed by Tukey post hoc test; $\mathrm{n}=7$ for each groups. 
A

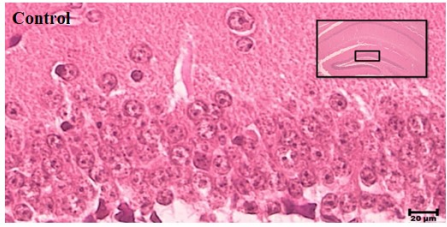

$\mathbf{B}$

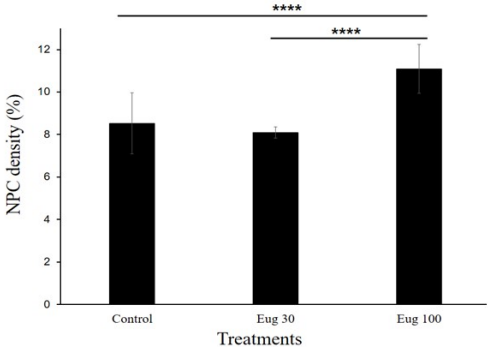

$\mathbf{E}$

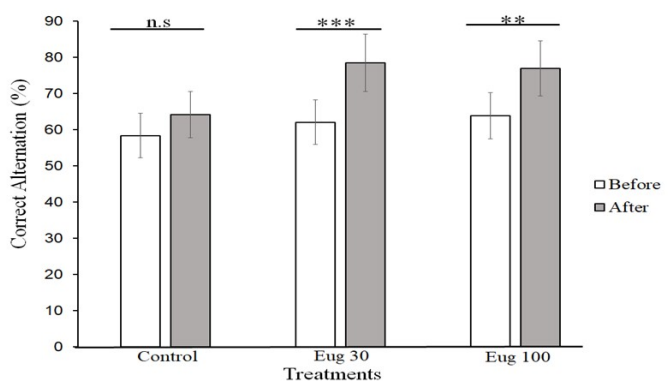

G

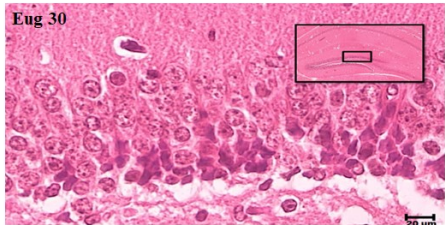

C

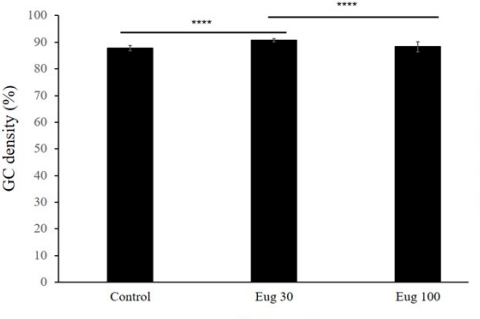

Treatments

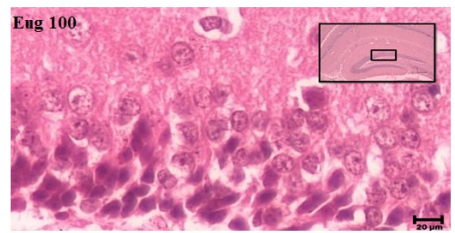

D

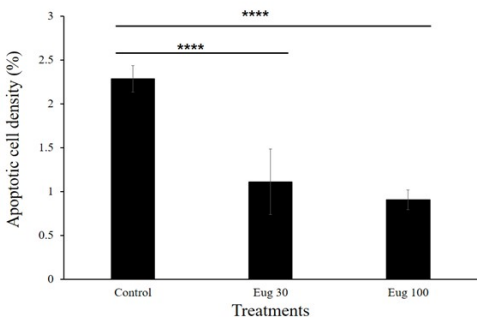

F

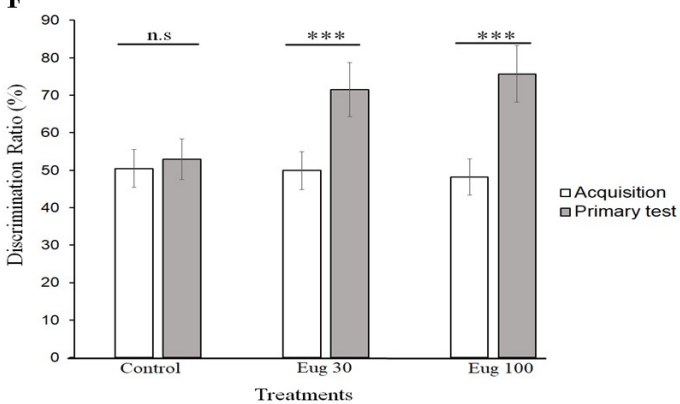

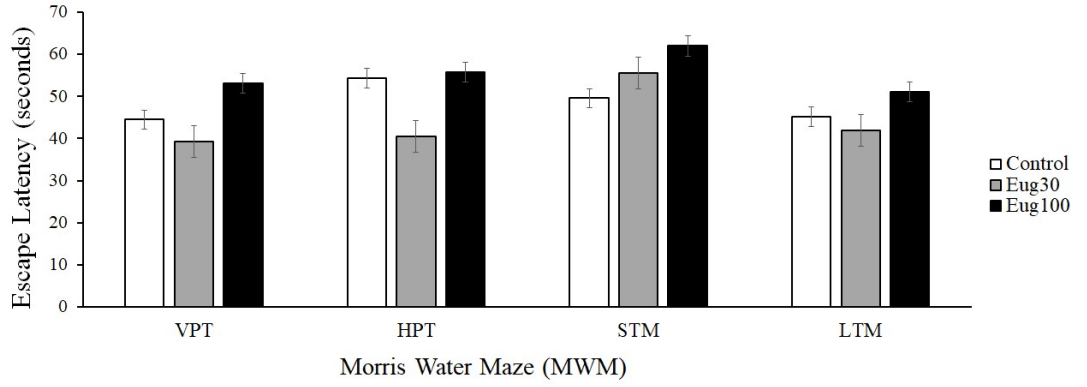

Figure 2: Neurogenesis and memory performance. (A) Representative of photomicrograph of DG using HE staining method in control, Eug30, and Eug100; (B) Putative NPCs density; (C) GCs density; (D) Apoptotic cells density; (E) Y maze correct alternation; (F) NOR discrimination ratio; $(G)$ MWM escape latency. * significantly different using one-way ANOVA followed by Tukey post hoc test; $n=3$ for each groups in HE staining and $n=7$ for each groups in behavioral test.

mice into two different objects, the familiar and new objects. We examined their ability to recognize these particular objects. The result of NOR test is shown in Figure 2F. Before eugenol was administered to mice, the DR in the acquisition were in similar level in each mouse ( $\mathrm{p}>0.05$; one-way ANOVA).

The learning-memory of mice in this research was also assessed by MWM test. We divided this test into the training sessions, which refer to VPT and HPT, and the primary tests which consisted of STM and LTM (Figure 2G). During the visible and hidden platform, Eug30 and Eug100 might showed slight reduction of escape latency, although these phenomena were not statistically different ( $>0.05$; one-way ANOVA). The same results were also found in short term and long term tests $(\mathrm{p}>0.05$; one-way ANOVA).

\section{DISCUSSION}

We sought to measure memory performance of mice using three main parameters: spatial memory, recognition memory, and learning-memory. Our results have suggested that the changes in learning-ability behavior are in correlation with neuroanatomical changes in mice brain. We observed dendritic complexity of neurons and cell densities in hippocampus to describe the differences of mice's memory related-behavior. We inferred that the increase of memory in this research occurred due to a better condition of neurons in hippocampus as reflected by higher dendritic length and intersections, as well as the putative NPCs and GCs density. Dendrites have crucial roles for processing a neural information since their arrangement will determine the 
synapses and both the branches and location of dendrite will affect the electrical properties that important for the circuit function ${ }^{[28]}$.

We have revealed that the improvement in mice behavior is probably supported by the increase profile of hippocampal dendrites. In this research, total dendritic lengths increased both in DG and basal part of CA1. Additionally, the number of intersections also increased, which means more profuse branching has been constructed. These branches enable neuron to collect more inputs. The dendritic lengths in this report would also be implicated in the increment of surface area of dendrites. Thus, we inferred this condition will increase the number of information gathered by dendrites from many presynaptic areas, so the probability of neuron to get and store memories would improve as well. Moreover, studies mentioned that the increase in total intersection and distance from soma also determine an excitatory postsynaptic potential (EPSP) that will contribute to neuronal firing ${ }^{[29]}$. Thereby, spatial and recognition memory in this research have increased significantly. This is also in accordance with previous research using voluntary exercise which had proved that a better memory performance of mice is highly correlated with improvement in dendritic structures and complexity in the adult hippocampus ${ }^{[30]}$.

In this research, eugenol increased dendritic complexity of neurons in DG and CA1. We suggest that this phenomenon might also have been caused by a certain protein that influence the mechanism of learning memory in the brain. Previous report demonstrated that eugenol can increase $\mathrm{BDNF}^{[20]}$. It is a neurotrophin that promotes different functions such as for neuronal survival, morphology, and plasticity ${ }^{[31]}$. BDNF can modulate the complexity of dendrites. It increases dendritic length of CA1 pyramidal neurons ${ }^{[32]}$, and also the granular cells in $\mathrm{DG}^{[33]}$. Thus, our results are tempting to suggest that the increase of dendritic complexity of neurons in DG and CA1 basal after treated by eugenol might have been associated with BDNF signaling.

It was interesting to discover in this research that the dendritic span was not showing any differences among the groups in DG and basal part of CA1. It suggests that the dendrites have grown in an appropriate way and considered normal. Although the dendrite structure has changed to become longer and contain many intersections, they were well-developed to the right direction. It will give a good implication to the proper signals transmitted by dendrites for the acquisition, consolidation, and retrieval phase. The chemoattractant, such as Sema3A, considerably contribute to guiding the apical dendrites to the expected location ${ }^{[34]}$. In contrast, an aberrant dendritic span will disrupt synaptic signals which affect memory stream ${ }^{[35]}$.

We observed that eugenol could increase neurogenesis in DG, as represented by a higher number of putative NPCs in this research. Neurogenesis is not only involving a cell development from proliferation to maturation, but also including synaptic integration. Neurons will develop dendritic branches and contribute to the formation of neural circuitry in hippocampus ${ }^{[36]}$. A previous study confirmed that voluntary exercise increased neurogenesis in DG, and it induced the increment of dendritic lengths ${ }^{[30]}$. Our studies support this causal relation by showing that eugenol can increase neurogenesis and it is in line with total dendritic lengths which implicated to a better learning memory. This nascent neurite will polarize its organelles and cytoskeleton to form dendrites. When it once formed, they will gradually grow and make new branches under certain biological process until it would become mature and build dendrite anchor. In this research, we found that Eug100 has successfully enhanced NPCs density, compared to control and Eug30. It might indicate that higher putative NPCs will impact to higher proliferation in DG. A previous study mentioned that eugenol has succeeded to raise proliferation in mesenchymal stem cells (MSCs) ${ }^{[37]}$. The GCs in this research have also increased in Eug30, which showed that the cells in this group have grown mature and differentiated. We have also noticed that eugenol attenuated the neuronal death in both treatments, implied that eugenol can improve cell survival abilities, as the previous report showed that eugenol has neuroprotective effects against aluminum toxicity ${ }^{[38]}$. This declining number of apoptotic cells indirectly increased the ease of neurogenesis in DG, which affects memory performance.

This research demonstrated that eugenol significantly increased spatial ability of mice. During the Y Maze test, mice were traveled to three different arms in a given time. The mice which demonstrate high spatial ability will move towards the new arm more often than turning back to the previous arm ${ }^{[39]}$. Therefore, its required to recall the last arm that had visited by mice. This process needs a complex signaling pathway, particularly in hippocampus of the brain. Hippocampus has proved to have a crucial role in spatial learning memory. Recent research has described that during spatial navigation, the hippocampus of the brain becomes active. Moreover, studies mentioned that the damage of the hippocampus will lead to the impairment of spatial memory ${ }^{[40]}$.

Previous studies examined the Y maze test to mice that induced by scopolamine-eugenol elaboration ${ }^{[15]}$. Scopolamine can impair hippocampal-dependent memory and it is acknowledged to evaluate the anti-amnesic activity. In their study, a combination of scopolamine and eugenol until a dosage of $50 \mathrm{mg} / \mathrm{kg}$ bw can improve spatial memory. In this current research, we demonstrated that eugenol alone could enhance the Y maze result compared to control. We also revealed that eugenol with a higher dosage (100 $\mathrm{mg} / \mathrm{kg}$ bw) still has a good effect on spatial learning memory, indicating that this dosage is still considered normal and did not give a bad side effect. Furthermore, scopolamine-eugenol in previous study subjected to mice for 14 days, while we administered eugenol for 30 days, meaning that eugenol plausibly could preserve its positive effect for a longer duration.

Besides its effect on spatial memory, the hippocampus, particularly the dorsal side, is also important for recognition memory ${ }^{[41]}$. During the NOR task, the memory would be stored and mice try to collect the characteristics of objects that later could be placed in different parts of the brain. However, when mice face new objects, the brain needs to reconsolidate and reorganize the memories of the previous object, implicating the fusion of new experiences or information ${ }^{[42]}$. In this study, the NOR primary test revealed that eugenol increased recognition memory both in Eug30 and Eug100. These groups also have significantly improved compared to the previous acquisition phases. Conversely, the control group did not show any differences, indicating that the mice's tendency to explore novelty has relatively equal either in acquisition or primary test. This increasing number is related to dendritic complexity of neurons of DG and CA1. As the first subregion of hippocampus that receives incoming signals, DG plays a key role in pattern separation, the ability to differentiate similar experiences or objects ${ }^{[43]}$. This ability allows mice to separate the old and new objects, and retrieve the previous memory when they were exposed to the novel objects.

Our results, however, showed that eugenol unable to decline escape latency in MWM test. This was plausibly caused by the lack of acquisition memory gained by mice since it was conducted once in a day for the trial phases. In this research, eugenol both at the lower and higher doses have not given a significant effect on learning memory during the training stages; then it somehow affected the rest of the primary test. This result might be also correlated with dendrites in CA3 which were not observed in this research. The CA3 
network is important for memory acquisition ${ }^{[44]}$. Therefore, although the dendrites increased in CA1, it would not affect the short and long term results, because the consolidation process was not wellconducted when the acquisition was not at the optimal phase. In addition, further work is needed to elucidate eugenol effect on MWM test alongside with dendrites observation in CA3. We also recommend that the training frequency should be increased, thus enable the mice will to get enough information for the test.

Studies have tried to prove the effectiveness of eugenol to prevent or cure a neurological disorder, such as Alzheimer disease ${ }^{[12]}$ and epilepsy ${ }^{[36]}$. This current work will enriched our knowledge on how eugenol effects dendrites and neurogenesis which would beneficial for neurodegenerative research. In respect to our findings, it can be suggested that eugenol might become a potential therapeutic candidate. Our study, however, have limitations such as the lack of information on dendritic spines. Therefore, more work in describing those characteristics and identify the neuron's dendritic tree would be necessary to comprehend the synaptic strength and electrical signals transmission. Molecular research also has to be conducted in order to connect the improvement of NPCs and dendrites with the the signal processing in hippocampus after treated by eugenol.

\section{CONCLUSION}

Eugenol increased spatial and recognition memory indicated by the higher correct alternations in Eug30 and Eug100 after mice tested using $\mathrm{Y}$ maze alternation, and also the higher discrimination ratio percentage in NOR test. Eugenol also increased dendritic length and intersections both in DG and basal part of CA1. The maximum dendritic span was not significantly different in DG and apical part of CA1. Eugenol increased the number of putative NPCs and GCs, and decreased the number of apoptotic cells in the DG, which supports an enhancement of hippocampal neurogenesis. In general, eugenol with $100 \mathrm{mg} / \mathrm{kg}$ bw dose demonstrated a better effect on hippocampal dendritic complexity of neurons.

\section{REFERENCES}

1. Ncube B, Finnie JF, van Staden J. In vitro antimicrobial synergism within plant extract combinations from three South African medicinal bulbs. J Ethnopharmacol. 2012;139(1):81-9.

2. Kaileh M, Berghe WV, Boone E, Essawi T, Haegeman G. Screening of indigenous Palestinian medicinal plants for potential anti-inflammatory and cytotoxic activity. J. Ethnopharmacol. 2007;113(3):510-6.

3. Kamatou GP, Vermaak I, Viljoen AM. Eugenol--from the remote Maluku Islands to the international market place: a review of a remarkable and versatile molecule. Molecules. 2012;17(6):6953-81.

4. Müller M, Pape HC, Speckmann EJ, Gorji A. Effect of eugenol on spreading depression and epileptiform discharges in rat neocortical and hippocampal tissues. Neuroscience. 2006. 140(2): 743-51.

5. Raja MRC, Srinivasan V, Selvaraj S, Mahapatra SK. Versatile and synergistic potential of eugenol: a review. Pharm Anal Acta. 2015;6(5):32-39.

6. Fathy M, Fawzy MA, Hintzsche H, Nikaido T, Dandekar T, Othman ME. Eugenol exerts apoptotic effect and modulates the sensitivity of HeLa cells to cisplatin and radiation. Molecules. 2019;24(21):3979.

7. Hasim F, Batubara I, Suparto IH. The potency of clove (Syzygium aromaticum) essential oil as slimming aromatherapy by in vivo assay. Int J Pharm Bio Sci. 2016;7(1):110-6.

8. Lin CH, Lin SH, Lin CC, Liu YC, Chen CJ, Chu CL, Huang HC, Lin MK. Inhibitory effect of clove methanolic extract and eugenol on dendritic cell functions. J Funct Foods. 2016;27:439-47.

9. Tao G, Irie Y, Li DJ, Keung WM. Eugenol and its structural analogs inhibit monoamine oxidase $\mathrm{A}$ and exhibit anitidepressantlike activity. Bioorg Med Chem. 2005;13(15):4777-88.

10. de Araújo Lopes A, da Fonseca FN, Rocha TM, de Freitas LB, Araújo E, Wong D, Lima Júnior R, Leal L. Eugenol as a promising molecule for the treatment of dermatitis: antioxidant and anti- inflammatory activities and its nanoformulation. Oxid Med Cell Longev. 2018;8194849.

11. Dubey K, Anand BG, Shekhawat DS, Kar K. Eugenol prevents amyloid formation of proteins and inhibits amyloid-induced hemolysis. Sci Rep. 2017;7:40744.

12. Irie Y. Effects of eugenol on the central nervous system: its possible application to treatment of alzheimer's disease, depression, and parkinson's disease. Curr Bioact Compd. 2006;2(1):57-66

13. Taheri P, Yaghmaei P, Tehrani HS, Ebrahim-Habibi A.. Effects of eugenol on Alzheimer's disease-like manifestations in insulin- and A $\beta$-Induced rat models. Neurophysiology. 2019;51:114-9.

14. Liu Z, Niu W, Yang X, Wang Y. Effects of combined acupuncture and eugenol on learning-memory ability and antioxidation system of hippocampus in Alzheimer disease rats via olfactory system stimulation. J Tradit Chin Med. 2012;33(3):399-402.

15. Garabadu D, Sharma M. Eugenol attenuates scopolamine-induced hippocampal cholinergic, glutamatergic, and mitochondrial toxicity in experimental rats. Neurotox Res. 2019;35(4):848-59.

16. Amaral DG, Scharfman HE, Lavenex P. The dentate gyrus: fundamental neuroanatomical organization (dentate gyrus for dummies). Prog Brain Res. 2007; 163:3-22.

17. Bird CM, Burgess N. The hippocampus and memory: insights from spatial processing. Nat Rev Neurosci. 2008;9(3):182-94.

18. Abrous DN, Koehl M, Le Moal M. Adult neurogenesis: from precursors to network and physiology. Physiol Rev. 2005;85(2):523-69.

19. Zhao C, Deng W, Gage FH. Mechanisms and functional implications of adult neurogenesis. Cell. 2008;132:645-60.

20. Irie Y, Itokazu N, Anjiki N, Ishige A, Watanabe K, Keung WM. Eugenol exhibits antidepressant-like activity in mice and induces expression of metallothionein-III in the hippocampus. Brain Res. 2004;1011(2):243-46.

21. Horch HW, Katz LC. BDNF release from single cells elicits local dendritic growth in nearby neurons. Nat neurosci. 2002;5(11):1177-84.

22. Pinchas M, Baranes D. Dendritic branch intersections are structurally regulated targets for efficient axonal wiring and synaptic clustering. PLoS ONE. 2013;8(12):e82083.

23. Arikkath J. Molecular mechanism of dendrites morphogenesis. Front Cell Neurosci. 2012;6(61):1-14

24. Juliandi B, Tanemura K, Igarashi K, Tominaga T, Furukawa Y, Otsuka M, Moriyama N, Ikegami D, Abematsu M, Sanosaka T, Tsujimura K, Narita M, Kanno J, and Nakashima K. Reduced adult hippocampal neurogenesis and cognitive impairments following prenatal treatement of the antiepileptic drug valproic acid. Stem Cell Rep. 2015;5(6):996-1009.

25. Bevins RA, Besheer J. Object recognition in rats and mice: a onetrial nonmatching-to-sample learning task to study 'recognition memory'. Nat Protoc. 2006;1(3):1306-11.

26. Weitzner DS, Engler-Chiurazzi EB, Kotilinek LA, Ashe KH, Reed MN. Morris water maze test: optimization for mouse strain and testing environment. J Vis Exp. 2015;22(100):e52706.

27. Cardiff RD, Miller CH, Munn RJ. Manual Hematoxylin and Eosin Staining of Mouse Tissue Sections. Cold Spring Harb Protoc. 2014(6):655 - 8.

28. Spruston N. Pyramidal neurons: dendritic structure and synaptic integration. Nat Rev Neurosci. 2008;9(3):206-21.

29. Lefebvre JL, Sanes JR, Kay JN. Development of dendritic form and function. Annu Rev Cell Dev Bi. 2015;31:741-77.

30. Redila VA, Christie BR. Exercise-induced changes in dendritic structure and complexity in the adult hippocampal dentate gyrus. Neuroscience. 2006;137(4):1299-1307.

31. Cohen-Cory S, Kidane AH, Shirkey NJ, Marshak S. Brain-derived neurotrophic factor and the development of structural neuronal connectivity. Dev Neurobiol. 2010;70(5):271-88.

32. Alonso M, Medina J H, and Pozzo-Miller L. ERK1/2 activation is necessary for BDNF to increase dendritic spine density in hippocampal CA1 pyramidal neurons. Learni Memory. 2015;11(2):172-8

33. De Vincenti AP, Ríos AS, Paratcha G, Ledda F. Mechanisms that modulate and diversify BDNF functions: implications for hippocampal synaptic plasticity. Front Cell Neurosci. 2019;13: 135)

34. Polleux F, Morrow T, Ghosh A. Semaphorin $3 \mathrm{~A}$ is a chemoattractant for cortical apical dendrites. Nature. 2000;404(6778):567-73. 
35. Nestor MW, Hoffman DA. Aberrant dendritic excitability: a common pathophysiology in CNS disorders affecting memory? Mol Neurobiol. 2012;45(3):478-487.

36. Ramirez-Amaya V, Marrone DF, Gage FH, Worley PF, Barnes CA. Integration of new neurons into functional neural networks. $J$ Neurosci. 2006;26: 12237-41.

37. Sisakhtnezhad S, Heidari M, Bidmeshkipour A. Eugenol enhances proliferation and migration of mouse bone marrow-derived mesenchymal stem cells in vitro. Environ Toxicol Pharmacol. 2018;57:166-74.

38. Said MM, Rabo MA. Neuroprotective effects of eugenol against aluminiuminduced toxicity in the rat brain. Arh Hig Rada Toksikol. 2017;68:27-37.

39. Tony DE, Vijaya T, Kumar DS, Kumar MS, Babu AN, Rao NR. Evaluation of memory enhancment activity and shock motivated brightness discrimination response by using Y-maze. Res J Pharm Biol Chem Sci. 2013;4(4):136-42.
40. Wang F, Song YF, Yin J, Liu ZH, Mo XD, Wang DG, Gao LP, Jing YH. Spatial memory impairment is associated with hippocampal insulin signals in ovariectomized rats. PLoS ONE. 2014;9(8):e104450.

41. Goulart BK, de Lima MN, de Farias CB, Reolon GK, Almeida VR, Quevedo J, Kapczinski F, Schröder N, and Roesler R. Ketamine impairs recognition memory consolidation and prevents learning-induced increase in hippocampal brain-derived neurotrophic factor levels. Neuroscience. 2010;167(4):969-73.

42. Clarke JR, Cammarota M, Gruart A, Izquierdo I, Delgado-García JM. Plastic modifications induced by object recognition memory processing. PNAS. 2010;107 (6):2652-57.

43. Yessa MA, Stark CEL. Pattern separation in hippocampus. Trends in Neuroscience. 2011;34(10):515-25.

44. Nakazawa K, McHugh TJ, Wilson MA, Tonegawa S. NMDA receptors, place cells and hippocampal spatial memory. Nat Rev Neurosci. 2004;5(5):361-72.

\author{
Abbreviations \\ BDNF : Brain-derived neurotrophic factor \\ CA1 : Cornu ammonis 1 \\ DDY : Deutchland denken yonken \\ DG : Dentate gyrus \\ DR : Discrimination ratio \\ EC : Entorhinal cortex \\ Eug30 : Eugenol $30 \mathrm{mg} / \mathrm{kg}$ bw \\ Eug100 : Eugenol $100 \mathrm{mg} / \mathrm{kg}$ bw \\ GCs : Granular cells \\ HE : Haematoxylin Eosin \\ HPT : Hidden platform trial \\ LTM : Long term memory test \\ MWM : Morris water maze \\ NOR : Novel object recognition \\ NPCs : Neural progenitor cells \\ STM : Shot term memory test \\ VPT : Visible platform trial
}

\title{
Potential Conflicts of Interests
}

None

Sponsor / Grants / Acknowledgments:

This work was supported by a grant from the Ministry of Research, Technology, and Higher Education, Indonesia, to Berry Juliandi (No. 4101/IT3.L1/PN/2019)

\section{Corresponding Author}

Berry Juliandi, Department of Biology, Faculty of Mathematics and Natural Sciences, IPB University (Bogor Agricultural University), Bogor, 16680, Indonesia. Email: bjuliandi@apps.ipb.ac.id 